\title{
IDENTIFICATION OF INFLUENCE OF PART TOLERANCES OF 3PWR-SE PUMP ON ITS TOTAL EFFICIENCY TAKING INTO CONSIDERATION MULTI-VALUED LOGIC TREES
}

\author{
Adam Deptuła \\ Opole University of Technology, Poland \\ Wroclaw University of Technology, Poland \\ Piotr Osiński \\ Wroclaw University of Technology, Poland \\ Marian Partyka \\ Opole University of Technology, , Poland
}

\begin{abstract}
This paper presents the way of identifying the influence of the tolerance of model pumps (TYPE 3PWR-SE) construction on the total efficiency. The identification of sensitive control dimensions (Value/Tolerance) of examined pumps has been made by means of the multi-valued logic and inductive decision trees. In order to confirm the obtained results, multiple-valued logic trees have been used in the paper according to algorithms for the minimization of individual logic functions. What is more, a specific monotonicity of values of the most key parameters has been determined for the investigated set of pumps having individual specification numbers.
\end{abstract}

Keywords: multiple-valued logic function, optimization, gear pump after tooth root undercutting, degree of parameters importance

\section{INTRODUCTION}

The gear pump constructions have been developed for over 400 years. Johannes Kepler was the creator of the first gear unit and he patented his solution in 1604. The primary application of the patented solution at that time was to pump water in dewatering of mines [1,30-31]. The valve-less and self-priming gear construction resistant to numerous contaminations present in the water removed from shaft wells very quickly replaced used at that time and hard to use piston pumps. The author of this solution saw a wider application of his invention. He did not exclude using his idea to remove bilge water on ships, force the water flow in park and garden fountains but also to compress air in the construction of blowers and exhausters. In 1636 Daniel Schwenter in his paper entitled Deliciae mathematicae oder mathematische und philosophische Erquickstuden presented a complete description of an external gear pump operation with the construction sketch. Particular attention was paid in this description to maintain the internal tightness "teeth of one of the wheels attack teeth of the second one and they do it so precisely that neither air nor water can go through the hull or in the middle, between the co-operating teeth or sides because there is no space between wheels and casing walls". This is why in the $17^{\text {th }}$ century much attention was paid to keeping appropriate dimension tolerance of co-operating displacement elements with the casing. The improvement of internal tightness is connected with the minimization of energy losses, increasing the transferred power and energy efficiency of the generator $[14-27,30]$. In addition, there are analytical methods to design the commutation unit in a hydraulic satellite motor [31, 32]. The total efficiency of gear pumps which are produced nowadays is equal to about $80-90 \%$ (for nominal pressured reaching $28 \mathrm{MPa}$ ). Such a large span is mainly connected with the adopted manufacturing tolerance. Due to a significant difficulty of establishing a precise relationship, the influence of the manufacturing tolerance of particular elements on the energy efficacy of the created pump, this paper tries to select critical deviations using the multiple-valued logic trees method.

The article focuses on the use of the multivalent logic trees to determine the validity of the parameters $\mathrm{n}$ and $\mathrm{pt}$ and the most important values of these parameters - from the viewpoint of optimum total efficiency $\eta_{c \text {. }}$ 
In turn, the optimal values of efficiency hc were determined by analyzing the impact of the tolerance of the pumps production. In the analysis a heuristic method and the method of induction of decision trees were used as the first. Control dimensions related to the five elements of particular pumps are: a drive gear wheel, an idler gear wheel, a set of bearings, a machine body and a plate. It was assumed that, the degree of sensitivity of control dimensions (value / tolerance) implies the differences in the efficiency of the tested pumps. The article presents only the results of a part of the research concerning the identification of the impact of tolerances on the pump design model (3PWR-SE) on the overall efficiency. A performed identification of sensitive control dimensions of pumps surveyed by various heuristic methods suggests that it is reliable - then subsequently the multivalent and inductive decision trees were used.

The Quine Mc-Cluskey algorithm of minimizing the partial multivalent logic functions allows to use the tree structures as the tools of application and support design process, optimization and decision-making $[6,25]$. If the design and/or operating parameters, hosting numeric values from a specific range, were designated by a set of logic variables, you can perform discretization of such numerical ranges. The set of all number combinations is a variants tree with the number of levels equal to the number of design and/ or operational parameters.

\section{THE RESEARCH OBJECT}

Gear pumps of the prototype series 3PWR-SE belonging to III group [17] were the research object. Wrocław University of Technology in co-operation with the company HYDROTOR S.A. designed the units. The experimental pump has been designed taking into consideration technological possibilities of the company HYDROTOR S.A. The innovation of the prototype unit is based on using oblique gears with a involute teeth modified in the lower and upper part of the profile. The modification in the lower part was made using the so-called tooth root undercutting. The outline has an elongated shape in the normal plane and its application causes the shortening of a part of the buttress and decreasing of the sealed area $[14,18]$. The area has been increased by cutting the oblique teeth. The inclination of the tooth line also favours the decrease in the pressure pulsation. The application of correction in the region of the apex was made in order to improve the co-operation of gears at the moment of entering the subsequent pair of gears into co-operation. In the end, gears got the polyevolvent outline. In order to determine the influence of the manufacturing technology on the level of the emitted noise $[14,29]$ it has been decided to produce gears using the grinding technology.

Pumps prototypes were entirely executed by the company HYDROTOR S.A. The research types of gear pumps with serial numbers and performance are summarized in the table 1 .
Table 1. Tested gear pumps

\begin{tabular}{|c|c|c|}
\hline Lp. & Pump model & Serial number \\
\hline 1. & 3PWR $-\mathrm{SE}-32 / 28-2-776$ & A 15010001 \\
\hline 2. & 3PWR $-\mathrm{SE}-32 / 28-2-776$ & A 15010002 \\
\hline 3. & 3PWR $-\mathrm{SE}-32 / 28-2-776$ & A 15010003 \\
\hline 4. & 3PWR $-\mathrm{SE}-32 / 28-2-776$ & A 15010004 \\
\hline 5. & 3PWR $-\mathrm{SE}-32 / 28-2-776$ & A 15010005 \\
\hline 6. & 3PWR $-\mathrm{SE}-32 / 28-2-776$ & A 15010006 \\
\hline 7. & 3PWR $-\mathrm{SE}-32 / 28-2-776$ & A 15010007 \\
\hline 8. & 3PWR $-\mathrm{SE}-32 / 28-2-776$ & A 15010008 \\
\hline 9. & 3PWR $-\mathrm{SE}-32 / 28-2-776$ & A 15010009 \\
\hline 10. & 3PWR $-\mathrm{SE}-32 / 28-2-776$ & A 15010010 \\
\hline
\end{tabular}

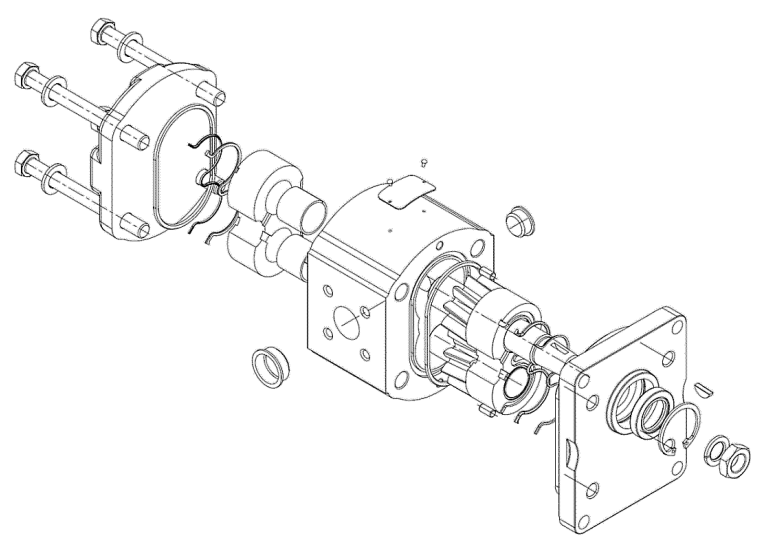

Figure 1. The exploded view of the prototype gear pump type 3PWR-SE

The analysed pump is characterised with a three-part construction. The consecutive parts are composed of:

- a plate with sealings of a roller, flanges fastening the pump to the coupling casing, holes for screws connecting the pump elements, dowel holes,

- casing, gears, slide bearing casings, discharge and suction ports, flow holes for screws connecting the casing elements, holes for screws of the flange connections and dowel holes.

\section{IDENTIFICATION OF INFLUENCE OF PART TOLERANCES OF 3PWR-SE PUMP ON ITS TOTAL EFFICIENCY TAKING INTO CONSIDERATION MULTI- VALUED LOGIC TREES}

Constructions of model and prototype pumps of 3PWRSE type can be used in particular in machines and marine machinery, deck and underdeck machinery as well as safety equipment. It is worth to mention here the hydraulic systems for life raft davits, control systems for anchoring systems and anchor-mooring systems (in particular micro pumps of the new generation) [12] and application in the construction of horizontal ramps of loading systems (it concerns in particular the integrated valve systems) [3]. There is a possibility of using the analysed pumps in hydraulic drives of winches. 
It is particularly worth paying attention to the possibility of applying given pumps in hard hydraulics used for underdeck ships' cranes [26]. There are many constructions of main and auxiliary displacement pumps used in hydraulic drive systems [4].

The optimization in the analysed units of model pumps was composed of two parts: The first part concerned the optimization of the pump tooth outline with the use of multi-valued logic trees. The second part was based on the use of logic decision structures in the optimisation of processing technology of elements having an influence on the total efficiency of the newly designed unit (the issue has been more deeply analysed in this article). It resulted in the limitation of dimensions and size tolerance where it is necessary and decreasing the accuracy class in places of little importance. The optimization of the technology caused a lowering of pumps production cost and an increase in their effectiveness. An advantage of shaved pumps is their higher total efficiency caused by low hydraulic and mechanical losses. Low values of roughness parameters of the tooth profile contribute to the improvement of the lubrication conditions of co-operating teeth. Beside the increase in the volumetric efficiency, the increase in the total efficiency as well as in the hydraulic and mechanical efficiency also took place. It is of particular importance in control distributors in difficult working conditions, designed for marine drilling equipment where there is high flow and small drop in pressure. It is also worth to mention here the hydraulic systems of the propeller pitch change, pump application in the control system and fuel systems for ship engines.

An example of the use of model pumps of the new generation is the drive system and the system of hydraulic control of the deck crane with heave compensator [13]. The hydraulic power unit is located separately on the deck near the crane. The unit is composed among others of the pump sub-unit. The application of model pumps of 3PWR-SE type, among others in the hydraulic power unit $\mathrm{ZZH}$ and the swivel feature unit ZMO can have an influence among others on:

- the possibility of decreasing the productivity pulsation,

- the application of three evolvent gears with an inclined outline and a zero lateral play has the biggest effect,

- decreasing vibrations,

- increasing the total efficiency,

- ameliorating conditions of reducing the sealed area by ensuring the covering level $\varepsilon$.

Besides, it can have an influence on the amelioration of the smooth and precise operation of the compensator. Its operation has not been smooth until now due to the mechanical and hydraulic loss in the passive compensator unit $\mathrm{ZKB}$ and changes in the direction of movement of the cylinder's piston with the change in the loading value. The crane presented in the paper [13] is the subject of research works in the Marine Mechatronics Department, the Faculty of Ocean Engineering and Ship Technology, Gdansk University of Technology.

\section{MEASURING RIG}

The static characteristics of the pump with multi-evolvental profile were determined using the rig shown in fig. 2 . In the rig, tested pump 1 is driven by $100 \mathrm{~kW}$ DC motor 2 working in tandem with SCR control system 20. The Pxob-94a motor and the DSI-0360/MN-503 thyristor control system make possible the smooth changing of pump rotational speed from 0 to $2000 \mathrm{rpm}[14,18]$.

Preliminary pressure pump 3 and tested pump 1 are protected by safety valves 7 and 8 . Tested pump 1 is loaded through throttle valve 10 . The pump's actual delivery $Q_{r z}$ is measured by PT-M1 turbine flowmeter 16 with a PT15100 flow sensor with a measuring range of $0-100 \mathrm{dm}^{3} / \mathrm{min}$. Instantaneous flow rates are recorded using a METEX microammeter type $M-3650 B$. Pump output torque $M$ is measured by $M t 1000$ torque sensor 21 with a measuring range of 0-000 Nm and a Beta 2002 recording system. The pump's number of revolutions $n$ is controlled on the driving motor shaft by a measuring system consisting of a photocell and digital counter 22. For this purpose a disc with internal holes is mounted on the motor shaft. There is a light source on one side of the disc with holes and a photocell on its other side. The photocell counts the number of electronic pulses dependent on the shaft rotational speed. This set is used solely to fix the prescribed speed of the driving system. Temperature $t$ of the liquid in the tank was measured by a set of thermistors (sensor PU 391/2 and meter PU 381/1).

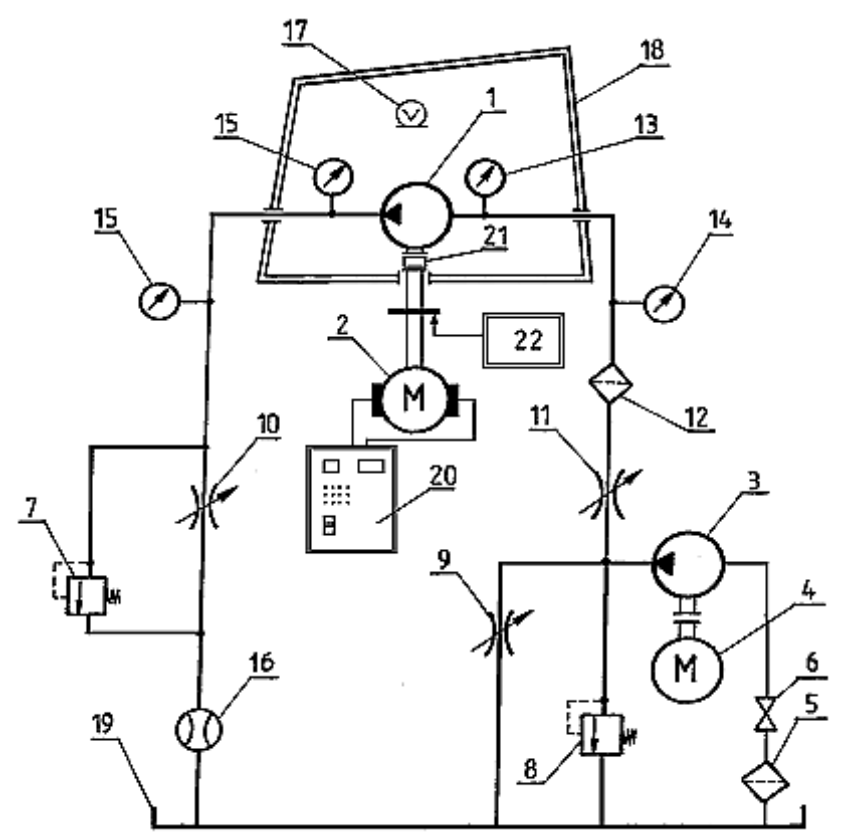

Figure 2. Schematic layout: 1 -tested pump, 2 -driving DC motor, 3 -feed pump, 4-AC motor, 5-suction filter, 6 -cut-off valve, 7, 8-safety valves, 9, 10, 11 - cut-off valve, 12 - drain filter,

13, 14-manovacuometer, 15 - pressure gauge, 16-flowmeter with microammeter, 17 - measuring microphones, 18 - sound

chamber, 19 -tank, 20 - electronic rpm adjustment system,

21 -torque sensor with recorder, 22 - photocell with measuring counter. 
Tests were carried out after the trial starting of the rig, i.e. after the operation of the pump and the safety valve and the indications of all the measuring instruments had been checked. Measuring began with setting the prescribed shaft rotational speeds $n=500,800,1000,1500$ and $2000 \mathrm{rpm}$. Pump loading was effected for $p_{t}=0,2,4,6,8,10,12,14,16,18$, $20,22,24,26,28,30$ and $32 \mathrm{MPa}$ [19]. The maximum forcing pressure was limited by the measuring range of torque meter 21. The static characteristics were tested at a constant working fluid temperature of $50^{\circ} \mathrm{C}$. Kinematic viscosity hydraulic oil was $36 \mathrm{~mm}^{2 / \mathrm{s}}$.

\section{IDENTIFICATION OF THE IMPACT OF TOLERANCES ON THE PUMP DESIGN MODEL (TYP 3PWR-SE)}

The object of the analysis was the control measurements ( value / tolerance ) for gear pumps prototype series listed in Table 1 . The aim of the analysis was to identify sensitive dimensions of the controls ( value / tolerance ) tested the pumps. Check dimensions of six pieces of data related to pumps: active gear KZP, corps KR, passive gear KZPn, cover $P K r$, plate $P L t$, a set of bearings KL and KLa .

The values and ranges sensitive dimensions of the audits have not been given due to data protection and tolerance design of the company producing the tested pumps. Therefore, the following designations were adopted:

- the strength of the tightening $P D s_{i}^{j}$ (measuring points from $P D s_{1}^{1}$ to $P D s_{4}^{10}$, where: $i=1,2, \ldots, 4 ; j=1,2, \ldots, 10$;

- active gear - $K Z P_{i}^{j}$ (measuring points from $K Z P_{1}^{1}$ to $K Z P_{16}^{10}$ , where: $i=1,2, \ldots, 16 ; j=1,2, \ldots, 10)$;

- corps- $K R_{i}^{j}$ (measuring points from $K R_{1}^{1}$ to $K R_{22}^{10}$, where: $i=1,2, \ldots, 22 ; j=1,2, \ldots, 10)$;

- passive gear - $K Z P n_{i}^{j}$ (measuring points from $K Z P n_{1}^{1}$ to $K Z P n_{16}^{10}$, where:: $\left.i=1,2, \ldots, 16 ; j=1,2, \ldots, 10\right)$;

- cover- $P K r_{i}^{j}$ (measuring points from $P K r_{1}^{1}$ to $P K r_{2}^{10}$, where: $i=1,2 ; j=1,2, \ldots, 10)$;

- plate- $P l t_{i}^{j}$ (measuring points from to $P l t_{7}^{10}$, where $i=1$, $2, \ldots, 7 ; j=1,2, \ldots, 10)$;

set of bearings- $K l_{i}^{j}$ (measuring points from $K l_{1}^{1}$ to $K l_{39}^{10}$ and measuring points from $K l a_{1}^{1}$ to $K l a_{39}^{10}$ where: $i=1,2$, $\ldots, 39 ; j=1,2, \ldots, 10)$, which adopted the $i$ - pump number ,$j$ - another measuring point.

The degree of sensitivity of control dimensions (Values/ Tolerance) implies differences in the values of the analyzed pumps efficiency. The value or tolerance change vulnerability during the measurement of control dimensions of details for particular pumps determines their importance rank. The determination of the most important places of particular details would make it possible to create a range of pumps characterized by the best efficiency parameters in the manufacturing process. The following 5 classification and optimization methods were used in the analysis: heuristic method, greedy algorithm, application of the neural network and application of the evolutionary algorithm [5].
A detailed calculation analysis of each of the methods will be presented in separate publications. Control measurements, both the most important ones and the less important ones, were determined in the identification of control measurements analysis. Especially important is the correct evaluation of tolerance during the construction of integrated decisionmaking methods [2, 6-8]. The most important measurements are those specified by all applied research methods. Less important measurements are control measurements determined by at least one of the applied research methods. As a result of calculations, 23 most important control measurements and 56 less important measurements were obtained.

Figure 3 shows the most important and less important control points for the detail set of bearings KL. Figure 4-6 shows the most important and less important control points for the details: active gear KZp and passive gear KZpn (Figure 4), corps KR (Figure 5), plate PLt (Figure 6).

The most important control points are highlighted in red whereas less important ones in yellow.
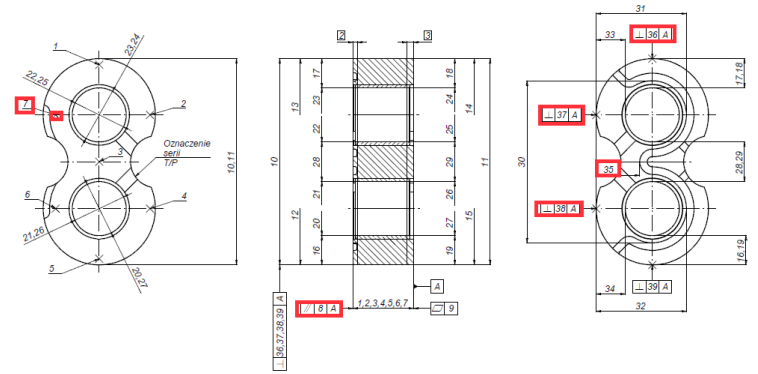

Figure 3. The most important and less important control points for details - set of bearings $K L$

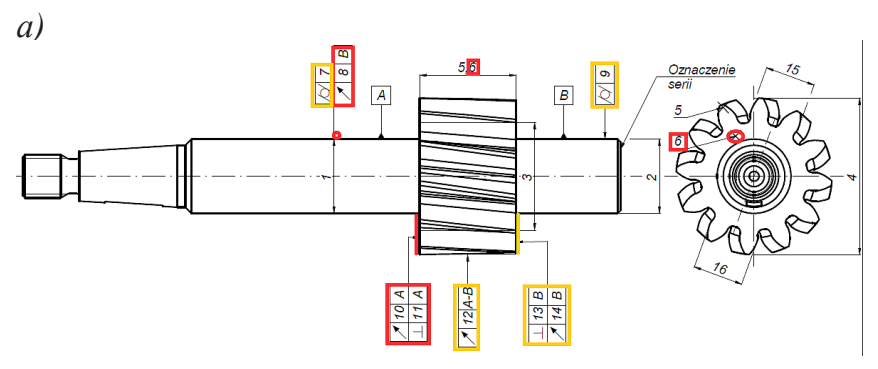

b)
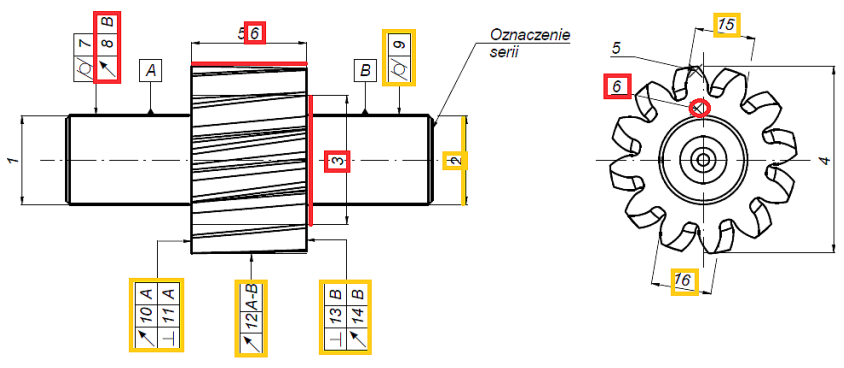

Figure 4. The most important and less important control points for details: a) active gear $K Z P, b$ ) passive gear KZpn 

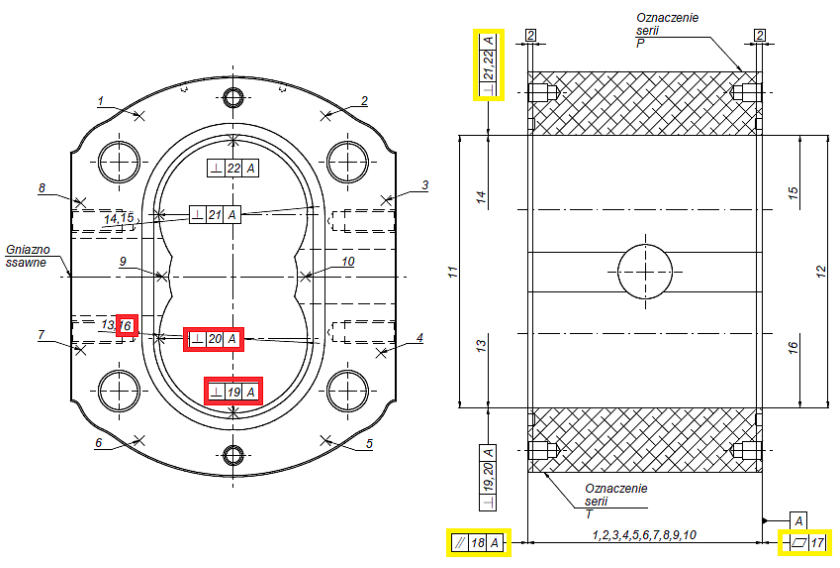

Figure 5. The most important and less important control points for details corps $K R$
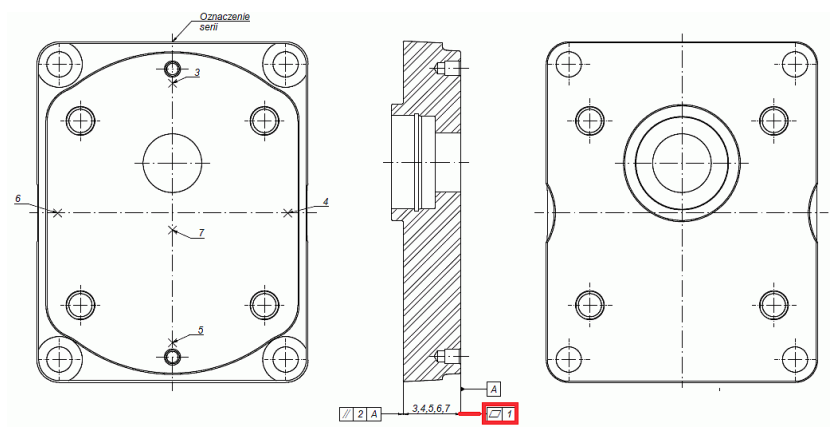

Figure 6. The most important and less important control points for details plate PLt

The Figures 7-11 show a comparison of the efficiency of the total ten gear pumps 3PWR - SE - 32/28 -2 - 776 for $\mathrm{n}=500,800,1000,1500,2000[\mathrm{rev} / \mathrm{min}]$.

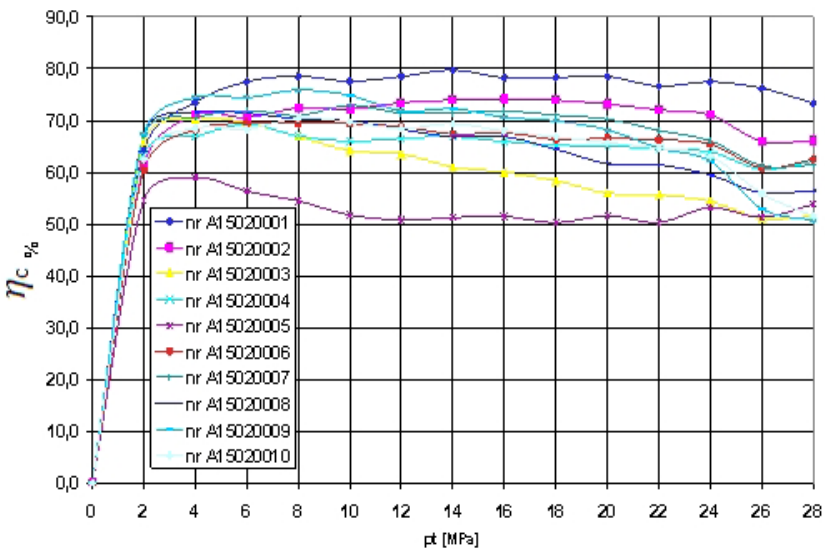

Figure 7. Total efficiency $\eta_{C}$ gear pumps 3PWR-SE for $n=500$ [rev $\left./ \mathrm{min}\right]$

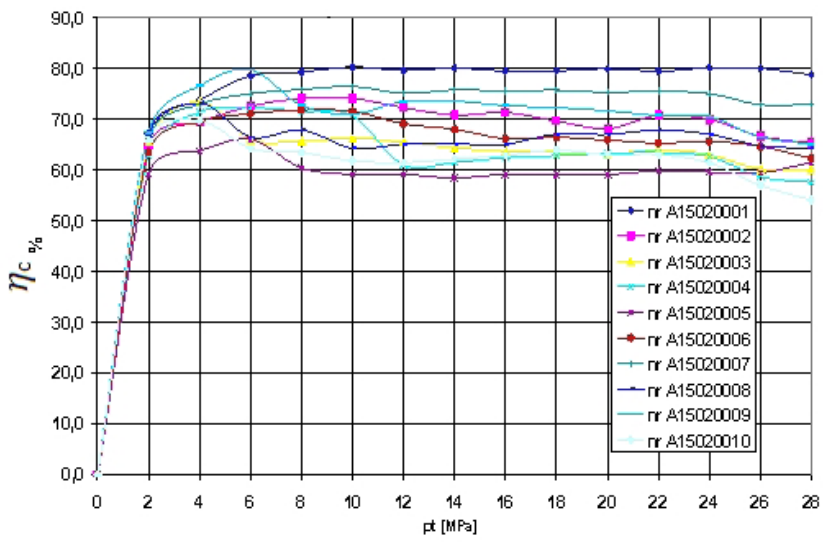

Figure 8. Total efficiency $\eta_{C}$ gear pumps 3PWR-SE for $n=800$ [rev $\left./ \mathrm{min}\right]$

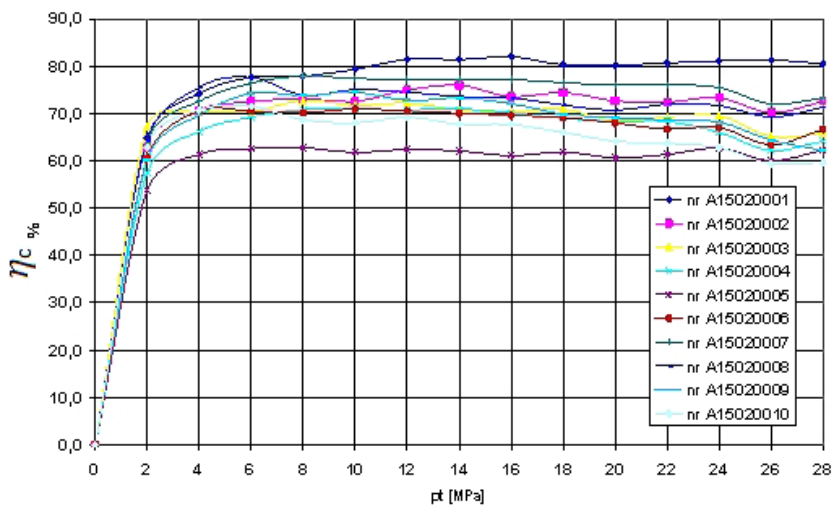

Figure 9. Total efficiency $\eta_{C}$ gear pumps 3PWR-SE for $n=1000$ [rev $\left./ \mathrm{min}\right]$

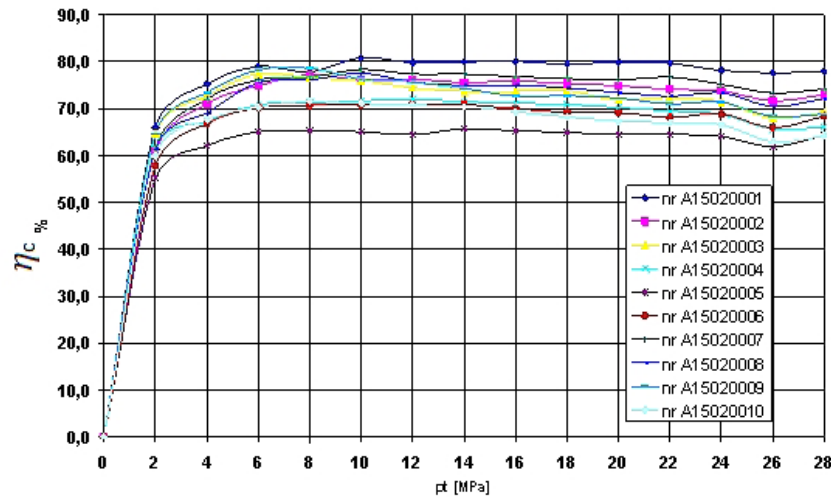

Figure 10. Total efficiency $\eta_{C}$ gear pumps 3PWR-SE for $n=1500[\mathrm{rev} / \mathrm{min}]$

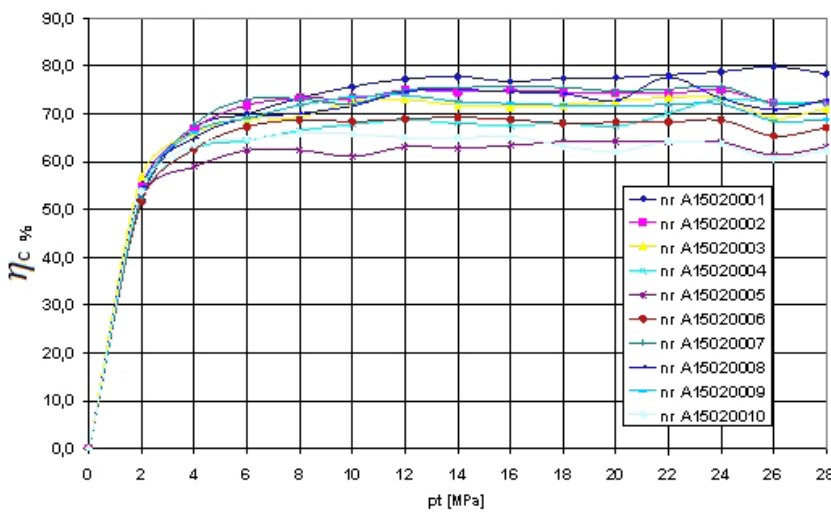

Figure 11. Total efficiency $\eta_{C}$ gear pumps 3PWR-SE for $n=2000[\mathrm{rev} / \mathrm{min}]$ 
Using a genetic algorithm one can get a better rank of decision parameters validity. However, this requires obtaining at least 200 to 300 or more results for pumps with the same number of cases, because it involves the correlation matrix inversion method. Due to the complexity of computing the exact methods (formal) of identification and classification can be used only for a small number of decision variables. Genetic algorithms were used in the analysis of the sensitivity control measurements, which are described in the reports on the development of innovative gear pumps with reduced emission of noise - implemented under the Operational Programme of Innovative Economy - carried out at the Technical University of Wroclaw. The results have not been published yet.

Therefore, the sequential determination of the validity rank for the most important parameters can be performed by using a multivalent logic trees method. Then, the algorithm of minimizing the individual logic functions is applied. Additionally, for this purpose, the monotonicity of the value of the most important parameters according to the numbers of pumps is determined, as well as Helwig's algorithm of the optimal selection of variables.

\section{APPLICATION OF MULTIPLE-VALUED LOGIC DECISION TREES}

If each structural and/or operational parameter, which takes the numerical values of the specified range will be marked with a fixed two - or polyvalent logical variable, we can perform discretization of such numerical ranges. The set of all number combinations creates a variants tree on the number of levels equal to the number of design and/or operating parameters, as in the case of traditional logic tree on a single level there can be only one logical variable.

The number of numerical values of a given interval is the number of branches in a single bundle and the number of all tracks from the bottom to the top of the logic tree equals exactly to the number of all combinations of the considered discrete intervals. Then it is due to extract real options only, that means achievable, ie. meeting the requirements of optimization. If in the logic trees there will be calculated by the number of branches of the real problems of discrete optimization with the possibility of exchange of levels of logic variables then only logic trees with the smallest number of branches can describe at the same time the true status of the validity of such parameters from the most important at the bottom to the least important at the top.

Using a multivalent logic, trees designated rank of importance of structural and operational parameters was established, taking into account the effect of tolerances construction. The study focused on two selected parameters: discharge pressure $\mathrm{Pt}$ and rotation speed $\mathrm{n}$.

Determination of the rank of the validity of parameters using multiple-valued trees logic requires the application of appropriate coding.

\section{QUINE-MCCLUSKEY ALGORITHM OF THE MINIMIZATION OF MULTIPLE-VALUED LOGIC FUNCTIONS}

The Quine-McCluskey algorithm makes it possible to find all prime implicants of a given logic function. It means that there is a shortened alternative, normal form SAPN $[25,34]$. The terms of incomplete gluing and elementary absorption have the main role in the search of prime implicants and are used for the APN of a given logic function.

Complex, multiple-valued logic functions determine the degree of importance of logic variables by changing the levels of the logic tree, from the most important (near the root) to the least important (on the top) because there is a generalisation of a Boolean quality index into a multiple-valued one; $\left(C_{k}\right.$ - $\left.k_{i} m_{i}\right)+\left(k_{i}+K_{i}\right)$, where $C_{k}$ - the number of branches of $k$ - level, $k_{i}$ - multiplicity of simplification on $k$-level, $m_{i}$ - value of $i$ - variable, $K_{\mathrm{i}}$ - the number of branches $(k-1)$ - level, out of which branches of $k$-level were formed which cannot be simplified. In this way it is possible to obtain the minimum complex alternative normal form. All transformations are described by the so-called Quine-McCluskey algorithm based on the minimization of individual partial multiple-valued logic functions.

The following transformation is called the consensus operation:

$$
A j_{o}\left(x_{r}\right)+\ldots+\left(A j_{m_{r-1}}\left(x_{r}\right)=A\right.
$$

where: $r=1$ and $A$ - a partial elementary product, the literals of which possess variables belonging to the set: $\left\{x_{1}, \ldots, x_{r-i}, x_{r+i}, \ldots, x_{n}\right\}$.

The following transformation is called the operation of reduction:

$$
A j_{u}\left(x_{r}\right)+A=A
$$

where: $0<\mathrm{u}<\mathrm{mr}-1,1 \leq r<n$ and $A$ - partial elementary product, the literals of which possess variables belonging to the set: $\left\{x_{1}, \ldots, x_{r-1}, x_{r+1}, \ldots, x_{n}\right\}$.(If the above equation takes place, then $A$ absorbs $A j_{u}\left(x_{r}\right)$. In the case of multi-valued weighting factors, we get [6-8]:

$$
\begin{aligned}
& w_{o} A j_{o}\left(x_{r}\right)+\ldots+w_{m_{r}-1} A j_{m_{r}-1}\left(x_{r}\right)= \\
& =\left(\min \left\{w_{o}, \ldots, w_{m_{r}-1}\right\}\right) \cdot A+\sum_{s=i_{o}, \ldots, i_{m_{r}-2}} w_{s} \cdot A \cdot j_{s}\left(x_{r}\right)
\end{aligned}
$$

where: $w_{i}$ - polyvalent weighting factor.

For example using the formula:

$$
A j_{o}\left(x_{r}\right)+\ldots+\left(A j_{m_{r-1}}\left(x_{r}\right)=A, \quad A j_{u}\left(x_{r}\right)+A=A\right.
$$

where: $A=A\left(x_{1}, \ldots, x_{r-1}, x_{r+1}, \ldots, x_{n}\right)$, 


$$
j_{u}\left(x_{r}\right)=\left\{\begin{array}{ccc}
m-1, & u=x_{r} \\
0, & & \\
0 \neq x_{r} &
\end{array} \quad 0 \leq u \leq m-1\right.
$$

successive stages of the multi-valued logic function minimization [25]: 020, 101, 200, 021, 111, 201, 210, 022, $121,202,211,212,221$ can be presented in the following way (Table 2): in terms of the validity rank of structural and/or exploitative parameters.

$$
f\left(x_{1}, x_{2}, x_{3}\right)=\left[\begin{array}{c}
j_{o}\left(x_{1}\right)\left[\left(j_{o}\left(x_{2}\right) j_{2}\left(x_{3}\right)+j_{1}\left(x_{2}\right) j_{o}\left(x_{3}\right)+j_{2}\left(x_{2}\right)\right)\right]+ \\
\left.+j_{1}\left(x_{1}\right)+j_{2}\left(x_{1}\right)\left[\left(j_{o}\left(x_{2}\right) j_{1}\left(x_{3}\right)+j_{1}\left(x_{2}\right)+j_{2}\left(x_{2}\right) j_{1}\left(x_{3}\right)\right)\right]\right]
\end{array}\right]
$$

The next steps to minimize shown in Tables 3, 4 and 5.

Table 2. NAPN and MAPN of a given logical function

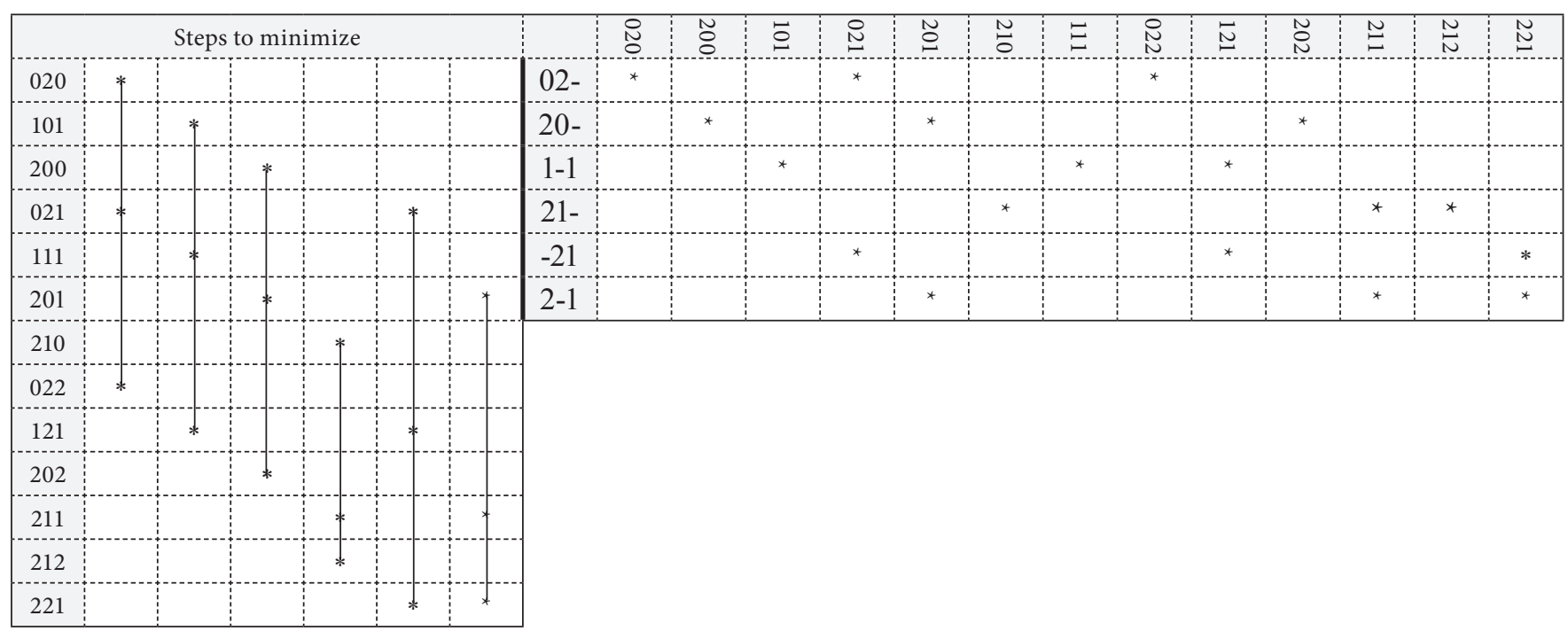

Finally, we receive both NAPN and MAPN of a given logical function saved in the form of numbers of $\mathrm{m}$-position system [6]:

$\{(02-),(20-),(1-1),(21-),(-21)\}$ and $\{(02-),(20-),(1-1),(21-),(2-1)\}$.

In the isomorphic interpretation of the Quine- McCluskey algorithm three steps are taken for the graphic matrix formalization $[5,25]$ :

- putting decision $\left(m_{1}, \ldots, m_{n}\right)$ - valued variables $x_{1}, \ldots, x_{n}$ in a certain order,

- creating the $n$ ! primary matrices, relative to all combinations of variables,

- prioritising the numbers relative to $\left(m_{1}, \ldots, m_{n}\right)$ the valence in the increasing order from the left side of the matrix,

- combining numbers and removing them (minimization). For example multiple-valued logical function $f\left(x_{1}, x_{2}, x_{3}\right)$, where $x_{1}, x_{2}, x_{3}=0,1,2$, written by means of numbers KAPN (Canonical Alternative Normal Form): 100, 010, 002, 020, 101, $110,021,102,210,111,201,120,022,112,211,121,212,221$, 122 , there is one MZAPN (Minimal Complex Alternative Normal Form) after the application of the Quine- McCluskey algorithm based on the minimization of individual partial multi-valued logical functions having 13 literals.

Logic trees with the smallest number of branches are called optimal and represent the structural guidelines for a designer
Table 3. The first stage of minimization logical function for $x_{3}$ and $x_{1}$

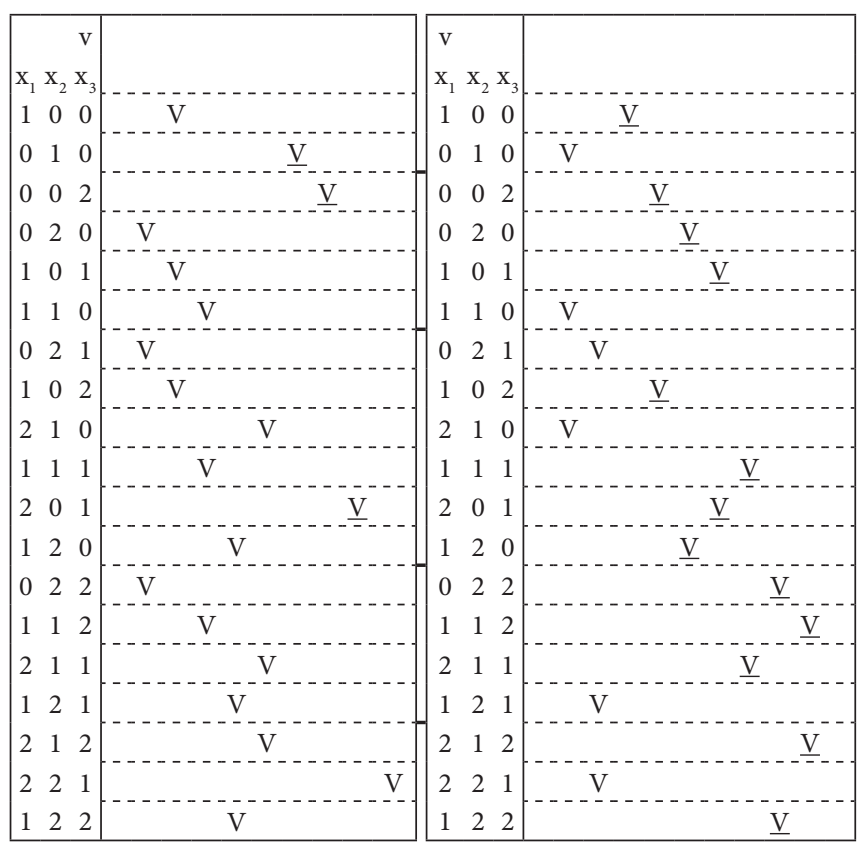


Table 4. The first stage of minimization logical function for $x_{2}$

\begin{tabular}{|c|c|c|c|}
\hline & $\mathrm{v}$ & & \\
\hline $\mathrm{x}_{1}$ & $\mathrm{x}_{2}$ & $\mathrm{x}_{3}$ & \\
\hline 1 & 0 & 0 & V \\
\hline 0 & 1 & 0 & $-\ldots$ \\
\hline 0 & 0 & 2 & - \\
\hline 0 & 2 & 0 & $\ldots \ldots$ \\
\hline 1 & 0 & 1 & $\mathrm{~V}$ \\
\hline 1 & 1 & 0 & $\mathrm{~V}$ \\
\hline 0 & 2 & 1 & $\underline{\mathrm{V}}$ \\
\hline 1 & 0 & 2 & $\mathrm{~V}$ \\
\hline 2 & 1 & 0 & $\underline{V}$ \\
\hline 1 & 1 & 1 & $\underline{V}$ \\
\hline 2 & 0 & 1 & V \\
\hline 1 & 2 & 0 & $\mathrm{~V}$ \\
\hline 0 & 2 & 2 & $\underline{V}$ \\
\hline 1 & 1 & 2 & $\mathrm{~V}$ \\
\hline 2 & 1 & 1 & V \\
\hline 1 & 2 & 1 & $\mathrm{~V}$ \\
\hline 2 & 1 & 2 & _ \\
\hline 2 & 2 & 1 & $-\ldots-\ldots-\ldots-\ldots-n-\ldots$ \\
\hline 1 & 2 & 2 & 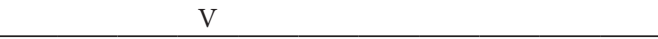 \\
\hline
\end{tabular}

The calculation of literals in the first step to minimize: $x_{1}: 19-2 \cdot 3+2+7=22, x_{2}: 19-4 \cdot 3+4+5=16, x_{3}: 19$ $-5 \cdot 3+5+4=13$.

Table 5. The second phase of minimization logical function for $x_{2}$ and $x_{1}$

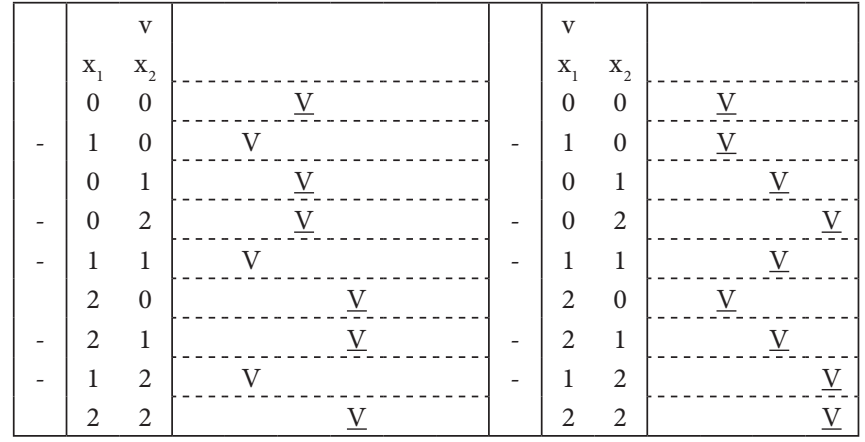

The calculation of literals in the second stage to minimize the $x_{1}: 9-0 \cdot 3+0+3=12, x_{2}: 9-1 \cdot 3+1+2=9$

Signs (v) mean that the partial elementary product written by numbers of $\left(m_{1}, \ldots, m_{n}\right)$-position system participates in sticking with those products that have a sign (v) in the same column.

Signs of splicing operation notation are written separately in columns, not in one column as in previous studies of literature cases of divalent.

In the case of identical multivalency of variables $x_{1}, \ldots, x_{n}$ of a given logical function, a set of prime implicants is obtained as a special case of various multivalency of variables

Figure 12 shows all possible the service stations multivalued logic function and not only optimal - MZAPN.
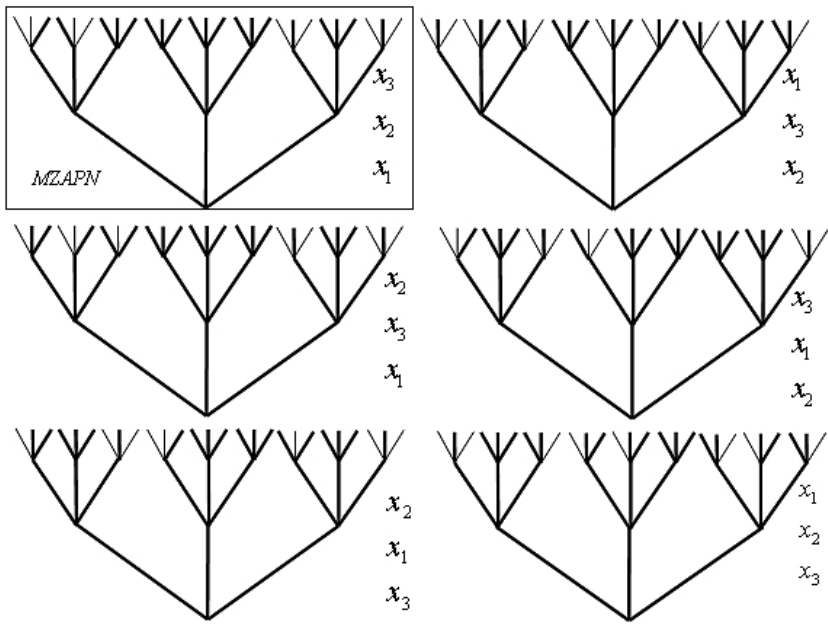

Figure 12. A multi-valued decision tree for the parameters $x_{1}, x_{2}, x_{3}$ with an appropriate layout of levels

\section{DETERMINATION OF THE RANK OF THE VALIDITY OF THE DESIGN PARAMETERS / OPERATING PUMPS MODEL (TYP 3PWR-SE), TAKING INTO ACCOUNT THE EFFECT OF TOLERANCES CONSTRUCTION}

Engineering practice requires correct evaluation of the mathematical model describing a given system with some variables. A proper mathematical model contains a group of functions joining different variables and describing connections between quantities in the system. Decision tables and logical functions $[4,6,8]$ can be applied in simulation of machine or in data classification and scheduling of measurement points [6, 7, 27-28]. Besides, there are dependence digraphs of the signal flow [9-15]. The game structure describes a space of possible solutions in order to find optimum objective functions $[4-5,15]$. Determination of the rank of the validity of parameters using multiple-valued trees logic requires the application of appropriate coding. The values of arithmetic discharge pressure Pt and the rotation speed $n$, taking into account the efficiency of the pumps model, were coded logically of the respective periods of the Tables 6-7: $n \cong 0,1,2,3,4$,

$P_{t} \cong 0,1,2$, for $n\{500,800,1000,1500,2000\} \mathrm{min}^{-1}$,

$P_{t}=\{2,4,6,8,10\},\{12,14,16,18,20\},\{22,24,26,28\} \mathrm{MPa}$. 
Table 6. General and specific logical encoding for the full range of change of the pressure Pt and $n=500$ and 800 [rev/min]

\begin{tabular}{|c|c|c|c|c|c|c|c|c|c|c|c|c|c|}
\hline \multicolumn{2}{|c|}{$\mathrm{P}_{\mathrm{t}}$} & \multicolumn{2}{|c|}{$\mathrm{n}$} & $\begin{array}{l}\text { A } 150 \\
10001\end{array}$ & $\begin{array}{l}\text { A } 150 \\
10002\end{array}$ & $\begin{array}{l}\text { A } 150 \\
10003\end{array}$ & $\begin{array}{l}\text { A } 150 \\
10004\end{array}$ & $\begin{array}{l}\text { A } 150 \\
10005\end{array}$ & $\begin{array}{l}\text { A } 150 \\
10006\end{array}$ & $\begin{array}{l}\text { A } 150 \\
10007\end{array}$ & $\begin{array}{l}\text { A } 150 \\
10008\end{array}$ & $\begin{array}{l}\text { A } 150 \\
10009\end{array}$ & $\begin{array}{l}\text { A } 150 \\
10010\end{array}$ \\
\hline$c^{*}$ & $\mathrm{MPa}$ & $c^{*}$ & $\min ^{-1}$ & $\%$ & $\%$ & $\%$ & $\%$ & $\%$ & $\%$ & $\%$ & $\%$ & $\%$ & $\%$ \\
\hline \multirow{5}{*}{0} & 2 & \multirow{13}{*}{0} & \multirow{13}{*}{500} & 64.1 & 61.6 & 66 & 63.3 & 54.5 & 60.5 & 66.9 & 67.3 & 67.3 & 62.4 \\
\hline & 4 & & & 73.5 & 71 & 70.3 & 66.9 & 59 & 68.2 & 70.6 & 71.5 & 74.4 & 68.4 \\
\hline & 6 & & & 77.5 & 70.6 & 69.5 & 69.3 & 56.3 & 69.4 & 71.9 & 71.4 & 74.4 & 68.3 \\
\hline & 8 & & & 78.5 & 72.4 & 66.9 & 67 & 54.5 & 69.4 & 70.9 & 70.3 & 75.9 & 70.4 \\
\hline & 10 & & & 77.6 & 72.2 & 64.2 & 66 & 51.8 & 69.4 & 72.9 & 69.9 & 74.8 & 69.7 \\
\hline \multirow{4}{*}{1} & 12 & & & 78.5 & 73.4 & 63.5 & 66.5 & 50.8 & 68.8 & 71.4 & 68.3 & 71.8 & 68.5 \\
\hline & 16 & & & 78.2 & 74.2 & 60 & 65.9 & 51.5 & 67.6 & 71.8 & 66.9 & 70.6 & 67.9 \\
\hline & 18 & & & 78.3 & 73.9 & 58.4 & 65.2 & 50.3 & 66.3 & 71 & 64.4 & 69.9 & 66.8 \\
\hline & 20 & & & 78.5 & 73.1 & 56 & 65.1 & 51.6 & 66.5 & 70.3 & 61.7 & 68.2 & 65.7 \\
\hline \multirow{4}{*}{2} & 22 & & & 76.6 & 72.1 & 55.6 & 64.5 & 50.3 & 66.3 & 68.1 & 61.4 & 64.6 & 64.6 \\
\hline & 24 & & & 77.5 & 71 & 54.4 & 63.9 & 53.1 & 65.4 & 66.1 & 59.4 & 62.1 & 63.1 \\
\hline & 26 & & & 76.2 & 66 & 51.1 & 60.6 & 51.3 & 60.9 & 61.2 & 56 & 52.9 & 55.9 \\
\hline & 28 & & & 73.3 & 66.1 & 51.5 & 62.1 & 53.8 & 62.5 & 61.4 & 56.5 & 50.7 & 51.5 \\
\hline \multirow{4}{*}{0} & 2 & \multirow{13}{*}{1} & \multirow{13}{*}{800} & 67.1 & 64.8 & 65.6 & 62.9 & 59.2 & 63.4 & 66.1 & 66.6 & 67.4 & 65.8 \\
\hline & 6 & & & 78.6 & 72.6 & 66 & 72.2 & 66 & 71.1 & 75 & 66.5 & 79.7 & 64.2 \\
\hline & 8 & & & 79.3 & 74.1 & 65.7 & 71.5 & 60.4 & 71.8 & 75.9 & 67.9 & 72.7 & 63.4 \\
\hline & 10 & & & 80.3 & 74.1 & 66.2 & 70.7 & 59.1 & 71.5 & 76.5 & 64.3 & 71 & 61.8 \\
\hline \multirow{5}{*}{1} & 12 & & & 79.6 & 72.3 & 65.5 & 61 & 59.1 & 69.1 & 75.1 & 65.1 & 73.5 & 61.4 \\
\hline & 14 & & & 80.1 & 70.8 & 64.3 & 61.5 & 58.5 & 68 & 75.8 & 65.1 & 73.6 & 62.2 \\
\hline & 16 & & & 79.5 & 71.3 & 63.7 & 62.4 & 59.1 & 66.2 & 75.6 & 65.1 & 72.7 & 62.9 \\
\hline & 18 & & & 79.5 & 69.6 & 63.4 & 62.8 & 59.1 & 66.4 & 75.7 & 67.1 & 72.3 & 63.9 \\
\hline & 20 & & & 79.9 & 68.1 & 63.1 & 63.3 & 59.1 & 65.9 & 75.3 & 67 & 71.7 & 63 \\
\hline \multirow{4}{*}{2} & 22 & & & 79.4 & 70.8 & 63.9 & 63.4 & 59.8 & 65.3 & 75.6 & 67.9 & 70.7 & 63 \\
\hline & 24 & & & 80.1 & 69.9 & 63 & 62.6 & 59.6 & 65.6 & 75 & 67.1 & 70.4 & 61.4 \\
\hline & 26 & & & 80 & 66.6 & 60.2 & 58.6 & 59.4 & 64.6 & 72.9 & 64.8 & 66.4 & 57 \\
\hline & 28 & & & 78.8 & 65.3 & 60.2 & 57.6 & 61.5 & 62.3 & 72.9 & 64.3 & 65.1 & 54.1 \\
\hline
\end{tabular}


Table 7. General and specific logical encoding for the full range of change of the pressure $P_{t}$ and $n=1000,1500$ and 2000 [rev/min]

\begin{tabular}{|c|c|c|c|c|c|c|c|c|c|c|c|c|c|}
\hline \multicolumn{2}{|c|}{$P_{t}$} & \multicolumn{2}{|c|}{$\mathrm{n}$} & $\begin{array}{l}\text { A } 150 \\
10001\end{array}$ & $\begin{array}{l}\text { A } 150 \\
10002\end{array}$ & $\begin{array}{l}\text { A } 150 \\
10003\end{array}$ & $\begin{array}{l}\text { A } 150 \\
10004\end{array}$ & $\begin{array}{l}\text { A } 150 \\
10005\end{array}$ & $\begin{array}{l}\text { A } 150 \\
10006\end{array}$ & $\begin{array}{l}\text { A } 150 \\
10007\end{array}$ & $\begin{array}{l}\text { A } 150 \\
10008\end{array}$ & $\begin{array}{l}\text { A } 150 \\
10009\end{array}$ & $\begin{array}{l}\text { A } 150 \\
10010\end{array}$ \\
\hline$c^{*}$ & $\mathrm{MPa}$ & $c^{*}$ & $\min ^{-1}$ & $\%$ & $\%$ & $\%$ & $\%$ & $\%$ & $\%$ & $\%$ & $\%$ & $\%$ & $\%$ \\
\hline \multirow{5}{*}{0} & 2 & \multirow{14}{*}{2} & \multirow{14}{*}{1000} & 64.9 & 62.9 & 67.3 & 57.5 & 53.8 & 60.5 & 63.9 & 64.3 & 60.1 & 62.9 \\
\hline & 4 & & & 74.2 & 70.7 & 70.3 & 66.2 & 61.4 & 70.5 & 72.6 & 75.5 & 69.6 & 70.7 \\
\hline & 6 & & & 77.6 & 72.5 & 70.4 & 69.3 & 62.6 & 70.4 & 76.4 & 77.7 & 74.3 & 71.5 \\
\hline & 8 & & & 77.9 & 73.1 & 72.8 & 70.8 & 62.8 & 70.2 & 77.9 & 73.8 & 73.8 & 68.7 \\
\hline & 10 & & & 79.4 & 72.6 & 71.8 & 70.9 & 61.8 & 71 & 77.4 & 75 & 74.5 & 68 \\
\hline \multirow{5}{*}{1} & 12 & & & 81.5 & 75 & 72.2 & 70.8 & 62.4 & 70.5 & 77.2 & 74.5 & 72.8 & 69.2 \\
\hline & 14 & & & 81.4 & 75.9 & 70.8 & 70.9 & 62.1 & 70.1 & 77.2 & 73.6 & 73.2 & 67.8 \\
\hline & 16 & & & 82 & 73.6 & 70.3 & 70.2 & 61.1 & 69.6 & 77.2 & 73.3 & 72.1 & 67.6 \\
\hline & 18 & & & 80.3 & 74.4 & 70.9 & 69 & 61.9 & 69.2 & 76.5 & 71.8 & 69.9 & 66 \\
\hline & 20 & & & 80.2 & 72.7 & 68.5 & 68.3 & 60.7 & 68 & 76 & 70.7 & 69.1 & 64.1 \\
\hline \multirow{4}{*}{2} & 22 & & & 80.7 & 72.4 & 69.3 & 68.3 & 61.4 & 66.7 & 76.1 & 72 & 68.7 & 63.7 \\
\hline & 24 & & & 81.1 & 73.3 & 69.6 & 66 & 62.7 & 67 & 75.5 & 71.7 & 68.2 & 62.8 \\
\hline & 26 & & & 81.3 & 70.2 & 65.2 & 62.2 & 60.1 & 63.4 & 72 & 69.3 & 64.4 & 59.4 \\
\hline & 28 & & & 80.5 & 72.5 & 65.8 & 64.2 & 62.3 & 66.7 & 73.3 & 71.3 & 62.2 & 59.6 \\
\hline \multirow{5}{*}{0} & 2 & \multirow{14}{*}{3} & \multirow{14}{*}{1500} & 66 & 60.8 & 64.6 & 61.4 & 55.1 & 57.8 & 61.6 & 61.3 & 64.6 & 60.1 \\
\hline & 4 & & & 75.2 & 71 & 72.6 & 67.3 & 62.1 & 66.8 & 72 & 69.1 & 73.4 & 67.7 \\
\hline & 6 & & & 79 & 74.9 & 77.4 & 70.8 & 65 & 70.2 & 76.1 & 75.5 & 78.2 & 70.4 \\
\hline & 8 & & & 77.8 & 77.2 & 76.6 & 71.3 & 65.4 & 70.7 & 76.7 & 76.1 & 78.6 & 71.6 \\
\hline & 10 & & & 80.8 & 76.1 & 75.9 & 71.7 & 65.1 & 70.9 & 78.3 & 77.5 & 76.3 & 71.1 \\
\hline \multirow{5}{*}{1} & 12 & & & 79.8 & 76.3 & 74.5 & 72 & 64.5 & 71 & 77.4 & 75.6 & 75.6 & 70.8 \\
\hline & 14 & & & 80 & 75.6 & 73.7 & 71.5 & 65.7 & 70.9 & 77.3 & 74.9 & 74.3 & 70.4 \\
\hline & 16 & & & 80.1 & 75.9 & 73.7 & 71.2 & 65.3 & 70 & 76.8 & 75 & 72.7 & 69.3 \\
\hline & 18 & & & 79.5 & 75.3 & 73.9 & 70.9 & 64.9 & 69.2 & 76.4 & 74.4 & 72.8 & 68.2 \\
\hline & 20 & & & 79.9 & 74.9 & 71.8 & 70.2 & 64.5 & 69.1 & 76.1 & 73.5 & 72.3 & 67.4 \\
\hline \multirow{4}{*}{2} & 22 & & & 79.7 & 74.1 & 72.4 & 69.5 & 64.5 & 68.2 & 76.7 & 72.7 & 71 & 66.9 \\
\hline & 24 & & & 78.2 & 73.8 & 71.4 & 68.8 & 64.1 & 68.9 & 75.2 & 73.3 & 71.4 & 66.6 \\
\hline & 26 & & & 77.6 & 71.7 & 67.9 & 65.6 & 61.9 & 66 & 73.4 & 70.5 & 68.3 & 62.9 \\
\hline & 28 & & & 77.9 & 73 & 69.3 & 66.1 & 64.4 & 68.4 & 74.2 & 72.1 & 68.9 & 64.2 \\
\hline \multirow{5}{*}{0} & 2 & \multirow{14}{*}{4} & \multirow{14}{*}{2000} & 52 & 54,7 & 56,9 & 51,8 & 52,5 & 51,7 & 52,5 & 54,7 & 54,2 & 53,9 \\
\hline & 4 & & & 67 & 66,9 & 65,9 & 62,5 & 58,9 & 62,6 & 67,7 & 65 & 66,2 & 63,5 \\
\hline & 6 & & & 70 & 71,8 & 68,9 & 64,4 & 62,3 & 67,3 & 73 & 69,1 & 69,1 & 64,5 \\
\hline & 8 & & & 73,3 & 73,2 & 69,3 & 66,5 & 62,4 & 68,7 & 73,1 & 70,1 & 71,8 & 66 \\
\hline & 10 & & & 75,7 & 73,1 & 72,5 & 67,8 & 61,1 & 68,4 & 72,1 & 71,7 & 73,5 & 65,8 \\
\hline \multirow{5}{*}{1} & 12 & & & 77,3 & 74,9 & 72,9 & 68,7 & 63,1 & 68,9 & 74,9 & 74,6 & 73,8 & 65 \\
\hline & 14 & & & 77,8 & 74,5 & 71,8 & 68 & 62,9 & 69,3 & 75,5 & 75 & 72,6 & 64,9 \\
\hline & 16 & & & 76,8 & 74,9 & 71,5 & 67,6 & 63,4 & 68,8 & 75,7 & 74,6 & 72,1 & 65,3 \\
\hline & 18 & & & 77,4 & 74,6 & 71,8 & 68,1 & 64,2 & 68 & 75,5 & 74,2 & 71,8 & 63,3 \\
\hline & 20 & & & 77,5 & 74,3 & 72,7 & 67,4 & 64,2 & 68,2 & 74,8 & 72,8 & 71,7 & 62,1 \\
\hline \multirow{4}{*}{2} & 22 & & & 78,2 & 74,2 & 73,4 & 70,1 & 64,1 & 68,2 & 75,2 & 77,6 & 71,9 & 64,2 \\
\hline & 24 & & & 78,8 & 74,9 & 73,2 & 73,1 & 64,1 & 68,7 & 75,7 & 73,2 & 72 & 63,7 \\
\hline & 26 & & & 79,8 & 72,3 & 69,1 & 72,3 & 61,4 & 65,4 & 72,2 & 70,9 & 68,5 & 60,5 \\
\hline & 28 & & & 78,4 & 72,2 & 71,1 & 72,2 & 63 & 67,1 & 72,6 & 72,9 & 68,7 & 62,3 \\
\hline
\end{tabular}

c- multivalent logic coding 
Table 8 show the specific and general logical coding for ranges of changes $P_{t}$ and $n$. in which at least 6 correspond pump efficiency defined with a tolerance of $5 \%$ and exactly 10 pumps meets prescribed performance with a tolerance of $5 \%$.

Table 8. General logical coding for ranges of changes $P_{t}$ and $n$. in which: a) at least 6 correspond pump efficiency defined with a tolerance of $5 \%$

\begin{tabular}{|c|c|c|}
\hline General logical coding & $P_{t}$ & $n$ \\
\hline 1 & 0 & 1 \\
\hline 2 & 0 & 3 \\
\hline 3 & 0 & 4 \\
\hline
\end{tabular}

Figure 13 shows multiple-valued logic trees for the table 8 .

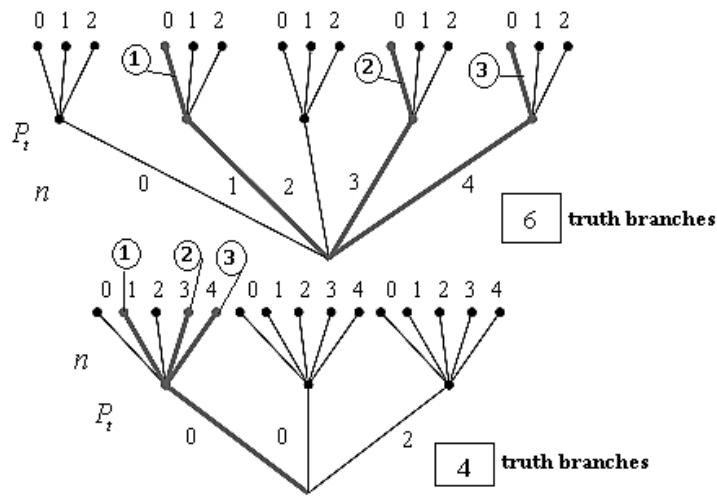

Figure 13. Multiple-valued logic tree for the table 8

General two or $n$ value logical coding is performed based on the tables of combinations of $\mathrm{n}$ logic variables which has $2^{n}$ or $m^{n}$ of all the rows.

Each logic variable corresponds graphically to a bundle of twigs coded by numbers 0,1 or $0,1, . ., m-1$. Logic variables are assigned to construction and exploitation parameters, so that their values describe the subsequent changes in such parameters. Two multivalent decision trees shown in the Figure 13 were received after applying the Quine Mc-Cluskey algorithm. In the case of discharge pressure $P_{\mathrm{t}}$ every branch $\{0,1,2\}$ refers to an appropriate range of arithmetic values i.e. $0-\{2,4,6,8,10\} \mathrm{MPa}, 1-\{12,14,16,18,20\} \mathrm{MPa}, 2-\{22,24$, $26,28\} \mathrm{MPa}$. Optimal twigs (in bold) in the picture means the true (optimal) ranges of $P_{t}$ and $n$-for which the criterion condition is met, i.e. max. $5 \%$ deviation and the value of maximum efficiency $\eta_{c}$. There were determined optimum values for $P_{t}$ a range: $\{2,4,6,8,10\} \mathrm{MPa}$, and the optimal values for $n: 800,1500,2000$. In addition, multivalent logic trees designated parameter Pt as more important, which is at the root of the optimal tree, i.e. with the fewest real twigs. This means that the most important measurement points (i.e. the value of control dimensions) should be searched in these value ranges which changes in the most significant way impact on the overall efficiency $\eta_{c}$. Using the logical decision structures there has been optimized the technology of processing elements affecting the overall efficiency of a newly designed unit.

\section{CONCLUSION}

The analysis of dimension tolerances and shape permitted in the end to select the control dimensions are: critical, important and less important. This resulted in a rational narrowness of the dimension tolerances and shape where it is necessary and in a reduction in an accuracy class in nonessential points.

The article focuses on the use of the multivalent logic trees to determine the validity of the parameters $n$ and $p t$ and the most important values of these parameters - from the viewpoint of optimum total efficiency $\eta_{c}$

In turn, the optimal values of efficiency hc were determined by analyzing the impact of the tolerance of the pumps production. In the analysis heuristic method and the method of induction of decision trees were used as the first. Control dimensions related to the five elements of particular pumps are: a drive gear wheel, an idler gear wheel, a set of bearings, a machine body and a plate. It was assumed that the degree of sensitivity of control dimensions (value / tolerance) implies the differences in the efficiency of the tested pumps.

A performed identification of sensitive control dimensions of pumps surveyed by various heuristic methods suggests that it is reliable - then subsequently the multivalent and inductive decision trees were used. The obtained parameters as adequate control points are repeated in the results of the identification with different multiplicity, but mostly steadily. Determination of the most important sites of individual details would allow for production of the best efficiency pumps in the series production process. 


\section{REFERENCES}

1. Abel F.: Johannes Kepler and his importance to modern science, Inter Nations Bonn - Bad Godesberg, 1971

2. Berghofer S., Reiter. M.: Formalizing the logic-automaton connection, In: Proc. of the 22nd International Conference on Theorem Proving in Higher Order Logics, LNCS No 5674, 147-163, 2009

3. Bueno M.J. M., Hernando M. D., Aguera A., FernandezAlba A.: Application of passive sampling devices for screening of micro-pollutants in marine aquaculture using LC-MS/MS, Talanta, Vol. 77, 4, 15, 2009, pp. $1518-1527$

4. Chang Q., Zhou H, Xie Z., Shen S.: Anchoring mechanism and application of hydraulic expansion bolts used in soft rock roadway floor heave control, International Journal of Mining Science and Technology, Vol. 23, 3, 2013, pp. $323-328$

5. Deptuła A.: Application of game graphs to describe the inverse problem in the designing of mechatronic vibrating systems. GRAPH-BASED MODELLING IN ENGINEERING, Springer, 2015 [accepted for print]

6. Deptuła A.: Application of multi-valued weighting logical functions in the analysis of a degree of importance of construction parameters on the example of hydraulic valves, International Journal of Applied Mechanics and Engineering, 19(3), 539-548, 2014

7. Deptuła A.: Game- tree structures with the complex complexity level as a tool in knowledge engineering. Systems in Management, Vol 2. Z. 2, ISSN 2084-5537, 2014

8. Deptuła A.: Integrated decision-making system in the study of acoustic an example of the gear pump Industrial transport and working machines (in Polish), 4(30), str. 65-71, ISSN 1899-5489, 2015

9. Deptuła A., Partyka M. A.: Decision optimization of machine sets with taking into consideration logical tree minimization of design guidlines, International Journal of Applied Mechanics and Engineering, Vol.19, No.3, University Press Zielona Góra, pp. 549-561 ISSN 142516554, 2014

10. Deptuła A., Partyka M.A.: Graphic matrix formalization of logical decision trees in the optimization of machine systems, GRAPH-BASED MODELLING IN ENGINEERING, Springer, 2015 [accepted for print]

11. Deptuła A., Partyka M. A.: Separate logical analysis of design guidelines in the machine systems modelling.
International Journal of Applied Mechanics and Engineering, Vol.17, No.3, pp. 779-790, ISSN 1425-1655, 2012

12. Dymarski P, Dymarski C.: A numerical model to simulate the motion of a lifesaving module during its launching from the ship's stern ramp, Polish Maritime Research, Vol. 21, 2, pp. 34-40, ISSN 2083-7429, 2014

13. Dymarski C.: Żuraw pokładowy z kompensacją nurzania, Napędy i Sterowanie, 17, 4, pp.112- 116, 2015

14. Kollek W. Osiński P.: Modelling and design of gear pumps, Wroclaw University of Technology Publishing House, Wrocław, 2009

15. Kollek W., Osiński P., Stosiak M., Wilczyński A., Cichoń P.: Problems relating to high-pressure gear micropumps, Archives of Civil and Mechanical Engineering, Vol. 14, nr 1,2014

16. Kollek W., Radziwanowska U.: Energetic efficiency of gear micropumps. Archives of Civil and Mechanical Engineering, Vol. 15, nr 1, 2015

17. Kudźma S. Kudźma Z.: Refined model of passive branch damper of pressure fluctuations, Journal of Theoretical and Applied Mechanics, vol, 53, nr 3, 2015

16. Osiński P., Deptuła A., Partyka M. A.: Discrete optimization of a gear pump after tooth root undercutting by means of multi-valued logic trees, Archives of Civil and Mechanical Engineering, Vol. 13. nr 4, 2013

19. Osiński P.: High-Pressure and Low-Fluctuation Internal Gear Pumps (in Polish), Wrocław University of Technology Publishing House, Wrocław, 2013

20. Osiński P., Kollek W.: Assessment of energetistic measuring techniques and their application to diagnosis of acoustic condition of hydraulic machinery and equipment, Archives of Civil and Mechanical Engineering, Vol. 13, 3, pp.167-172, 2013

21. Osiński P.: Modelling and design of gear pumps with modified tooth profile, Saarbrücken : LAP Lambert Academic Publishing, 2014

22. Osiński P., Kollek W., Wilczyński A.: The use of a series of Renard in the design of hydraulic and pneumatic components (in Polish), Hydraulika i Pneumatyka, 2010

23. Partyka M. A.: Some remarks on the Quine - Mc Cluskey minimization algorithm of multiple- valued partial functions for design structures. - 7th Inter. Cong. Log. Method. Phil. Sc., Salzburg, Austria, 1983 
24. Partyka M. A.: The Quine- Mc Cluskey minimization algorithm of individual multiple- valued partial functions for digital control systems. - 3rd Inter. Confer. Syst. Engin., Wright State University, Dayton, USA, 1984

25. Partyka M.A.: Algorytm Quine’a-Mc Cluskeya minimalizacji indywidualnych cząstkowych wielowartościowych funkcji logicznych, Studia i Monografie Nr 109, Politechnika Opolska - Oficyna Wydawnicza, Opole, 1999.

26. Rudnicki J.: The evaluation of the vibration measurement usability of electronic indicator LEMAG „PREMET C”. Journal of Polish CIMAC, Vol. 7, 2, pp. 167-172, 2012

27. Shwnoy P.P.: Game trees for decision analysis. Theory and decision, 44(2), April, pp.149-171, 1998

28. Shiue Y.R., Guh. R.S.: The optimization of attribute selection in decision tree-based production control systems. The International Journal of Advanced Manufacturing Technology, 28, pp.737-746, 2006

29. Stryczek J., Stryczek S.: Gear pumps - a brief history (in Polish), Part 1. SINH. Sterowanie i Napęd Hydrauliczny, 1994

30. Stryczek S.: Hydrostatic Drives (in Polish), Vol. I, II. WNT, Warsaw., 1995

31. Stryczek S.: Two hundred years of hydrostatic drive, In: Drives and control hydraulic '96. Scientific-Technical Conference, Szklarska Poreba (in Polish), June 1996, Wroclaw University of Technology Publishing House, 1996

32. Śliwiński P.: Flow of liquid in flat gaps of the satellite motor working mechanism, Polish Maritime Research 2(82) 2014 Vol 21; pp. 50-57

33. Śliwiński P.: The basics of design and experimental tests of the commutation unit of a hydraulic satellite motor, Volume 16, Issue 4, September 2016, Pages 634-644 Archives of Civil and Mechanical Engineering, 16, 4, 634-644, 2016

34. Quine W. V.: The problem of simplifying truth-functions, American mathematical monthly, 59, pp.521- 531, 1952

\section{CONTACT WITH THE AUTHOR}

\author{
Adam Deptuła \\ e-mail:a.deptula@po.opole.pl \\ Opole University of Technology, 75 Ozimska Street \\ 45-233 Opole \\ Poland \\ Wroclaw University of Technology \\ 7/9 Ign. Łukasiewicza Street, 50-371 Wroclaw \\ Poland \\ Piotr Osiński \\ e-mail:piotr.osinski@pwr.edu.pl \\ Wroclaw University of Technology \\ 7/9 Ign. Łukasiewicza Street, 50-371 Wroclaw \\ Poland \\ Marian Partyka \\ e-mail:a.partyka@po.opole.pl \\ Opole University of Technology \\ 75 Ozimska Street, 45-233 Opole \\ Poland
}

